NBER WORKING PAPER SERIES

\title{
USING INVESTMENT DATA TO ASSESS THE IMPORTANCE \\ OF PRICE MISMEASUREMENT
}

\author{
Diego Comin \\ Working Paper 10627 \\ http://www.nber.org/papers/w10627
NATIONAL BUREAU OF ECONOMIC RESEARCH
1050 Massachusetts Avenue
Cambridge, MA 02138
July 2004

I am grateful to Jess Benhabib, Hyunbae Chun, Jan Eberly, Mark Gertler, Lars Hansen, Bart Hobijn, Boyan Jovanovic, John Leahy, Ned Nadiri, Sergio Rebelo, Plutarchos Sakellaris, Tom Sargent, Kevin Stiroh, Gianluca Violante, Karl Whelan, Ed Wol. and the participants at NYU, the New York Fed, the Stern Macro lunch, the University of Pennsylvania and at the NBER conference on Productivity and Macroeconomics and the CEPR-ECB conference on Productivity and Prices for comments, suggestions and for helpful conversations. Financial assistance from the C.V. Starr Center is gratefully acknowledged. Please direct correspondence to diego.comin@nyu.edu. The views expressed herein are those of the author(s) and not necessarily those of the National Bureau of Economic Research.

(C2004 by Diego Comin. All rights reserved. Short sections of text, not to exceed two paragraphs, may be quoted without explicit permission provided that full credit, including $(\subset$ notice, is given to the source. 
Using Investment Data to Assess the Importance of Price Mismeasurement Diego Comin

NBER Working Paper No. 10627

July 2004

JEL No. C6, D9, E2

\section{ABSTRACT}

This paper presents a new approach to assess the role of price mismeasurement in the productivity slowdown. I invert the firm's investment decision to identify the embodied and disembodied components of productivity growth. With a Cobb-Douglas production function, output price mismeasurement only should affect the latter. Contrary to the mismeasurement hypothesis, I find that in the Post-War period, disembodied productivity grew faster in the hard-to-measure than in the non-manufacturing easy-to-measure sectors, and that disembodied productivity slowed down less in the hard-to-measure than in the easy-to-measure sectors since the 70's. These results hold a fortiori when capital and labor are complements.

Diego Comin

Department of Economics

New York University

269 Mercer Street, 725

New York, NY 10003

and NBER

diego.comin@nyu.edu 


\section{Introduction}

Measured productivity growth is affected by the mismeasurement of the growth rate of the output deflators. A failure to adjust for the quality improvements of output will bias downwards the measure of productivity growth. For a variety of reasons, ${ }^{1}$ measurement problems are more serious in construction and in some service sectors (retail and wholesale trade, finance and insurance and general services). These hard-to-measure sectors have experienced lower growth rates of total factor productivity (TFP) in the post-war period, as can be appreciated in the first column of table $1 .{ }^{2}$ This observation has lead many to consider the degree of mismeasurement of the output deflators as a key factor in the variation of productivity growth across sectors. ${ }^{3}$ Since the 1970's the US economy has suffered a slowdown in the annual growth rate of total factor productivity of about 1.2 percentage points. ${ }^{4}$ This slowdown has not been homogeneous across sectors. As illustrated in the second column of table 1, it has been concentrated in the sectors whose output is hard to measure. Since these sectors have traditionally experienced lower productivity growth rates, the cross-sectional distribution of productivity growth has become more dispersed after 1970. Some authors have associated this higher dispersion with the worsening of the mismeasurement problems in the hard-to-measure sectors. Baily and Gordon [1988] have suggested that an important component of the slowdown in retail and finance can be due to the unmeasured improvements in the convenience of the services provided in those sectors. Bresnahan [1986] estimates large unmeasured effects on the total factor productivity of the finance sector associated with the adoption of mainframes computers. Dranove, Shanley and White [1991] conclude that the bias in

\footnotetext{
${ }^{1}$ Historically, much more data were collected on agricultural and manufacturing commodities and their prices than were collected in services; moreover, for many commodities, one has publicly available data on the characteristics for individual items that are relevant to the measurement of output while this detail is unavailable on the performance characteristics of doctors, lawyers and stockbrokers. In many service sectors it is not exactly clear what is being transacted. Finally, service output often depends on the interaction with the user and thus is more difficult to standardize.

${ }^{2}$ This differential is equally large when we measure productivity with labor productivity (Baily and Gordon [1988] and Griliches [1994]).

${ }^{3}$ See Griliches [1992] for this argument and further references.

${ }^{4}$ The size of the slowdown is very robust to the cuttoff date. However 1970 seems an appropriate cuttoff since it isolates, as much as possible, the productivity measures from variation associated with the business cycle. This is the case because the measure of the output gap computed by the Congressional Budget Office was at about the same level in 1960, 1970 and 1997.
} 
the health-care price level has increased over time. ${ }^{5}$

The goal of this paper is to assess the relative importance of mismeasurement as a determinant of the variation in productivity growth across sectors and as a culprit of the productivity slowdown. To address these questions, I propose a new approach based on the assumption that firms observe the relevant prices with no bias. If this is the case, we can infer the importance of the bias in the BEA deflators by inverting the firm's decisions. More specifically, I consider the firm's investment policy and investigate how using a biased price series would affect the measured embodied and disembodied productivity growth. ${ }^{6}$ For a Cobb-Douglas production function, the marginal product of capital is linear in nominal sectorial output and in the level of productivity embodied in the new vintage. Interestingly, the only effect that the price of output has on the marginal product is through the nominal level of output. Hence, if nominal output is properly measured, the series of embodied productivity obtained by inverting the firm's investment decision will be neutral to any output price mismeasurement. The disembodied component is the residual in productivity after taking into account the growth in the (properly quality-adjusted) capital stock. Therefore, in the Cobb-Douglas case, the bias in the output price deflator shows up one-for-one in our estimate of disembodied productivity. $^{7}$

This result provides the basis for the tests on the relative importance of output price mismeasurement relative to other factors. If mismeasurement of the output deflator is the key determinant of the cross-sectional variation in TFP growth, we should observe that the disembodied component in the hard-to-measure sectors grows substantially more slowly than in those sectors that do not suffer from severe measurement problems.

Surprisingly, this is not the case empirically. With the exception of manufacturing, the sectors where output growth is easy to measure have lower growth rates of the

\footnotetext{
${ }^{5}$ Griliches [1994] has taken a related route. He suggests a compositional change in favor of the sluggish hard-to-measure as the likely candidate to explain the productivity slowdown. Sichel [1997] has convincingly argued that the compositional change can account for a very minor fraction of the decline in measured ptoductivity leaving open only the door of a within sector decline in productivity. That is the route analyzed in this paper.

${ }^{6}$ This distinction dates back to Solow [1959] who argued that increases in productivity may come both from installing new more productive capital and from improving symmetrically the productivity of all the vintages. He denoted the first as embodied productivity growth and the second as disembodied.

${ }^{7}$ Interestingly, this result also holds in the presence of any sort of mismeasurement in the prices of the capital input in the sector as shall be shown in section 3 (corollary 4 ).
} 
disembodied component than the hard-to-measure sectors. This necessarily implies that the cross-sectional variation of TFP growth is influenced by other "real" factors that are more relevant than price mismeasurement.

A second question that we can investigate is whether a worsening of the mismeasurement problems in the hard-to-measure sectors can account for the productivity slowdown. In this event, the growth rate of the disembodied component should have declined more in the hard-to-measure than in the easy-to-measure sectors since the 1970s. But again, this is not what we observe. In the data, there has been a larger decline in the growth rate of disembodied productivity in the easy- than in the hard-to-measure sectors. Hence, the role of mismeasurement in the productivity slowdown is also dominated by other factors.

One may wonder whether the Cobb-Douglas assumption is too stringent and whether these conclusions hold when capital and labor are complements, which is the empirically relevant alternative hypothesis (Antràs [2001]). In section 4.4, I show that the role of mismeasurement for productivity growth seems even more limited when we allow for more general patterns of substitution between the inputs.

These results are in sharp contrast with previous work. The hedonics literature has tried to provide more exact measures of quality adjusted-output by estimating the relationship between different attributes of the goods and services and their price. ${ }^{8}$ This approach is affected by two problems. First, it requires a comprehensive description of the characteristics of the goods. This is difficult to obtain specially for the output of the hard-to-measure sectors. Second, most of the available detailed data sets needed to build hedonic price indexes do not cover the pre 1970 period. Consequently, it is very difficult for this research agenda to infer whether the mismeasurement problems have become worse in the last thirty years.

A newer approach proposed by Hamilton [2001] and Costa [2002] has tried to identify the CPI bias by estimating the income elasticity of food and recreation (defined as entertainment plus reading) using cross-sectional micro data pooled across many years and using these estimates to measure the increase in households' real income over time controlling for changes in prices and in demographic characteristics. They both find that during the 1970s there was an important upward bias (about 2.5 percent per year) in the CPI,

\footnotetext{
${ }^{8}$ For a critical survey and references see Hulten [2002].
} 
higher than in the 80s and 90s (about 0.6 percent) and in the 60s (Costa, 0.4 percent). The spirit of this empirical strategy is similar to the one proposed here in that it uncovers the degree of mismeasurement by inverting the agents' choices (consumption in Hamilton [2001] and Costa [2002] and investment here). Interestingly the Hamilton-Costa strategy has the additional advantage of providing an absolute measure of the importance of mismeasurement, while the methodology proposed in this paper only can provide a measure of the importance relative to other factors. Nevertheless, the Hamilton-Costa strategy also faces some difficulties that leave room for further examination. ${ }^{9}$

I begin the paper with an illustration of the identification strategy for embodied productivity in a simplified setting where this can be done by comparing the investment output ratio to the growth rate of sectorial nominal output deflated by some aggregate deflator. By inspecting the trends in these variables, we can understand the intuition of the empirical findings. Section 3 formalizes these intuitions in a more general framework and proves the neutrality results. Section 4 contains the implementation of the mismeasurement tests and several robustness checks. Specifically, I consider various alternatives for the interest rates, the inclusion of adjustment costs and more general specifications for the production functions. The findings are very robust to these variations. Section 5 concludes.

\footnotetext{
${ }^{9}$ First, there are some data problems. The reporting of the food expenditures is sensitive to the survey method in ways that affect the estimate of the bias during the 70s. Defining recreational goods is hard. For example, reading is included in Costa's definition, but reading could be used for educational purposes as well. The increase in college enrollment in the 70s may be driving the reported increase in the share of recreation in expenditures instead of the unmeasured real income as Costa argues. This leads to a second criticism. In order to assign the average deviation from the share of expenditures predicted by demographics, relative prices and income to CPI bias the authors must assume that this relationship is stable. Omitting some relevant variable will result in a wrong assessment of the CPI bias. For example, if new technologies are developed in the 70s that make nonfood goods more attractive and that are complements to entertainment, ceteris paribus the consumer will tend to increase her share of expenditures in recreation and will reduce her share in food. Of course, the approach proposed in this paper is also subject to biases if the problem of the firm is misspecified. However, since my tests apply to the sum of the output deflator bias and the disembodied improvements in production, the risk of dealing with an unstable relationship and incurring in an omitted variable bias is substantially lower. A second advantage of the approach proposed here is that the quality of the data required to implement it is quite high.
} 


\section{The smoking gun}

Consider a multisector economy. Firms have access to a constant returns to scale technology. Without loss of generality, we can aggregate firms into sectors indexed by $i$. Each sector's output $\left(Y_{i t}\right)$ is produced according to the following Cobb-Douglas production function:

$$
Y_{i t}=Z_{i t} J_{i t}^{\alpha_{i}} L_{i t}^{1-\alpha_{i}}
$$

where, $\alpha_{i}$ is the capital share, $L_{i t}$ is employment, $Z_{i t}$ is disembodied productivity, and $J_{i t}$ is quality-adjusted capital which, following Solow's terminology, I refer to as jelly capital. The law of motion for jelly capital is as follows:

$$
J_{i t+1}=\left(1-\delta_{i}\right) J_{i t}+A_{i t+1} I_{i t}
$$

where $\delta_{i}$ is the depreciation rate, $I_{i t}$ is investment and $A_{i t+1}$ reflects a potential failure by the BEA to adjust perfectly investment for the efficiency embodied in the new capital vintage. $^{10}$

Firms maximize the expected present discounted value of profits taking as given the distribution of labor $\left(L_{i t}\right)$ and the price of final output $\left(P_{i t}\right)$. I assume that the interest rate is constant and equal to $R-1$, the price of investment is also constant and equal to $P_{i}^{I}$, and that $A_{i t}$ evolves according to the following common knowledge stochastic process:

$$
A_{i t+1}=\left(1+\gamma_{A i}\right) A_{i t} e^{\varepsilon_{i t}}
$$

where $\gamma_{A_{i}}$ denotes the average growth rate of embodied productivity in sector $i$ and $\varepsilon_{i t} \sim N\left(-\frac{\sigma_{A i}^{2}}{2}, \sigma_{A i}^{2}\right)$ is white noise. No restriction is imposed on $\left\{Z_{i t}\right\}$.

I introduce mismeasurement of the prices by assuming that firms observe perfectly the prices of the output they produce and the inputs they purchase, but the BEA may measure them imperfectly. The timing of the model is as follows: every period $t$, firms

\footnotetext{
${ }^{10}$ Comparing equations (1) and (2) it is clear that $Z_{i}$ affects symmetrically all the capital vintages while improvements in $A_{i}$ are embeded only in new vintages.
} 
produce output, observe the random variables for period $t+1$ and decide how much to invest to build up Jelly capital for period $t+1$.

Formally, the problem of the representative firm in the $i^{\text {th }}$ sector is as follows :

$$
\underset{\left\{I_{\tau}\right\}_{\tau=t}^{\infty}}{\operatorname{Max}} E_{t} \sum_{\tau=t+1}^{\infty} R^{-(t-\tau)}\left[P_{i \tau} Y_{i \tau}-P_{i}^{I} I_{i \tau}\right]
$$

s.t (1) and (2).

It is easy to check that optimal investment induces the following level of Jelly capital:

$$
J_{i t}=D_{i} A_{i t} P_{i t} Y_{i t}
$$

with $D_{i}=\left[\frac{\alpha\left(1+\gamma_{A i}\right)}{\left[R\left(1+\gamma_{A i}\right)-\left(1-\delta_{i}\right)\right] P_{i}^{I}}\right]$

Isolating $I_{i t}$ from the law of motion for Jelly capital, multiplying both sides by $\frac{P_{i}^{I}}{P_{i t} Y_{i t}}$ and using expression (3), we reach the following expression for the investment-output ratio as a function of the growth rate of nominal sectorial output and of the growth rate of embodied productivity.

$$
\frac{P_{i}^{I} I_{i t}}{P_{i t} Y_{i t}}=P_{i}^{I} D_{i}\left[\frac{P_{i t+1} Y_{i t+1}}{P_{i t} Y_{i t}}-\left(1-\delta_{i}\right) \frac{A_{i t}}{A_{i t+1}}\right]
$$

An increase in $Z_{i}, P_{i}$ or $L_{i}$ has a positive effect on the investment-output ratio. But, since the production function is Cobb-Douglas, this effect operates only through the growth rate of nominal output. This implies that, after controlling for the growth rate of nominal output, the other movements in the investment output ratio must be attributed to variation in the growth rate of $A_{i}{ }^{11}$ By inverting this investment function we can identify the growth rate of $A_{i}$.

$$
\frac{A_{i t}}{A_{i t+1}}=\frac{1}{1-\delta_{i}}\left[\frac{P_{i t+1} Y_{i t+1}}{P_{i t} Y_{i t}}-\left(\tilde{D}_{i}\right)^{-1} \frac{P_{i}^{I} I_{i t}}{P_{i t} Y_{i t}}\right]
$$

\footnotetext{
${ }^{11}$ Note also, that we cannot identify separately the depreciation rate and the growth rate of embodied productivity. Since we are only interested in the evolution of disembodied productivity, this is an advantage because any mismeasurement of the depreciation rate across sectors or over time will be automatically reflected in the measured growth rate of $A_{i}$ leaving unaffected the identified growth rate of disembodied productivity.
} 
where $\tilde{D}_{i}=\frac{P_{i}^{I} \alpha_{i}\left(1+\gamma_{A i}\right)}{R\left(1+\gamma_{A i}\right)-\left(1-\delta_{i}\right)} \cdot 12$

In principle, the presence of biases in the prices measured by the BEA may affect the recovered series for both embodied and disembodied productivity. However, for the Cobb-Douglas case, the identification of the rate of embodied productivity in equation (4) just requires the series for nominal output and nominal investment. If the BEA measures of these variables are unbiased, the growth rate of embodied productivity will be unaffected by any possible mismeasurement of the output deflator. The mismeasurement will fully show up in the identified growth rate of disembodied productivity. This observation is the key for the mismeasurement tests. If there is a systematic upward bias in the output deflators of the hard-to-measure sectors, we should observe that, ceteris paribus, the growth rate of $Z$ is lower in those sectors. Furthermore, if the bias has increased since the 1970s, we should observe that, ceteris paribus, the growth rate of $Z$ has declined in the hard-to-measure sectors.

To identify disembodied productivity, we just need to subtract the contribution of jelly capital from labor productivity. Given equation (4), this is the same as subtracting the growth rates of embodied productivity and the price level from productivity growth as in equation (5).

$$
\frac{Z_{i t+1}}{Z_{i t}}=\left(\frac{Y_{i t+1} / L_{i t+1}}{Y_{i t} / L_{i t}}\right)^{1-\alpha_{i}}\left(\frac{A_{i t}}{A_{i t+1}}\right)^{\alpha_{i}}\left(\frac{P_{i t}}{P_{i t+1}}\right)^{\alpha_{i}}
$$

In section 4.2 , we shall see that the growth rate of embodied productivity in the nonmanufacturing easy-to-measure sectors during the period 1960-97 has been much larger than in the hard-to-measure sectors. As a result, the growth rate of disembodied productivity in the latter has been higher than in the former despite the important differential in productivity growth in favor of the non-manufacturing easy-to-measure sectors. The intuition for this result can be illustrated with figures 1 and 2 that display the time series for the investment output ratio and the share in the aggregate nominal output for the manufacturing, the hard-to-measure and the non-manufacturing easy-to-measure sectors. Firms in the non-manufacturing easy-to-measure sectors have invested a large fraction of their value added (34 percent) despite the low growth rate of their nominal output (6.6 percent). This can only be an optimal decision by the firms if the growth rate of the productivity embodied in the new capital installed in these sectors has been

\footnotetext{
${ }^{12}$ Hobijn [1999] develops an equation very similar to this one for a one sector economy.
} 


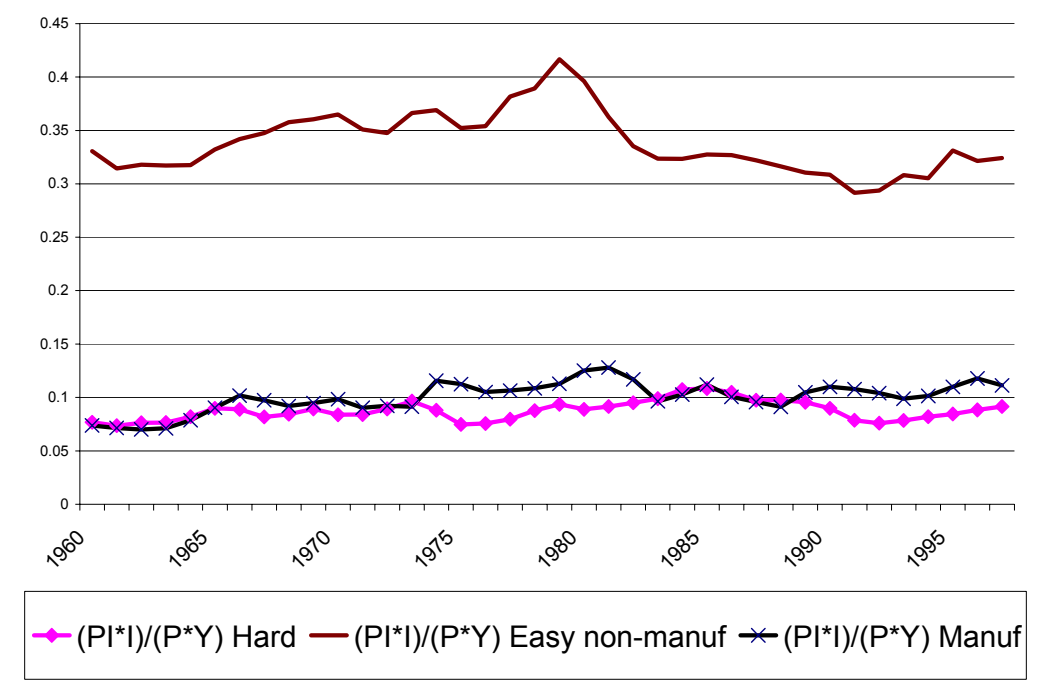

Figure 1: Investment output ratio by sector.

very large (equation (4)). The opposite occurs in the hard-to-measure sector. In these sectors, firms have invested a relatively small fraction of their value added (8.7 percent) despite the large growth rate of their nominal output (8.2 percent). This unmistakably indicates a low growth rate of embodied productivity. As a result, the ranking of sectors by their growth rates disembodied productivity implies that there are other elements more important than price mismeasurement for the cross-sectional variation in productivity growth.

The second main finding from our analysis is that the productivity slowdown cannot be explained by a worsening of the mismeasurement problems in the hard-to-measure sectors, despite the larger decline in productivity growth experienced by these sectors since 1970. Specifically, there has been a larger acceleration of the growth rate of $A$ in the easy-to-measure than in the hard-to-measure sectors and this differential is sufficient for the slowdown in disembodied productivity since 1970 to be larger in the easy-to-measure than in the hard-to-measure sectors.

There are two reasons for the larger increase in the growth rate of $A$ in the easy-tomeasure sectors. First, the manufacturing sectors have experienced an acceleration in the investment output ratio since 1970 (from 8.5 to 10.6 percent) while the growth 


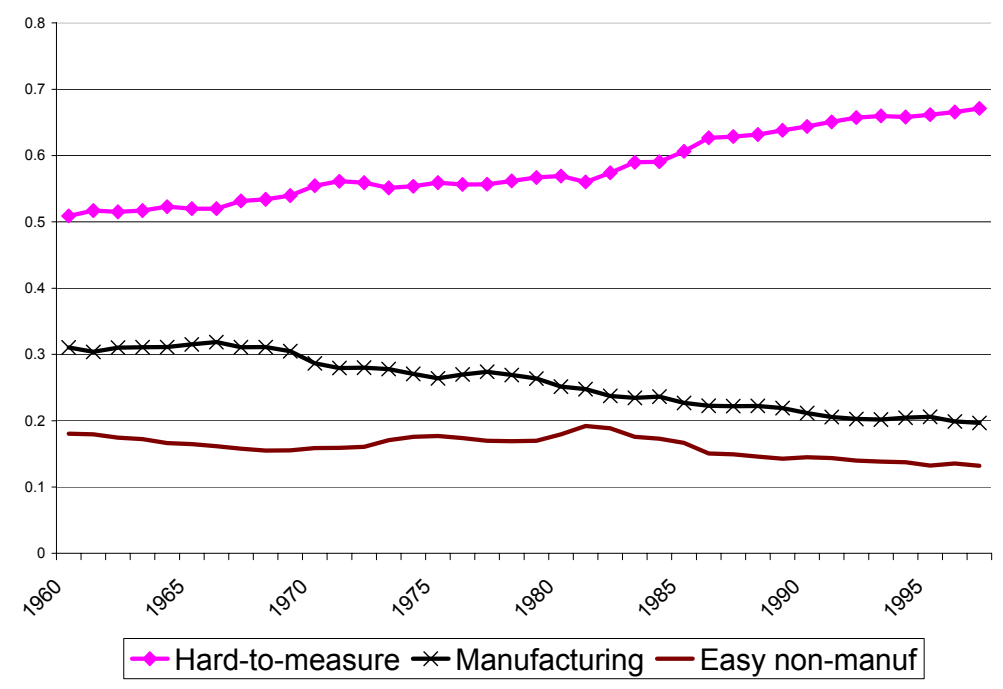

Figure 2: Share in private non-residential nominal output.

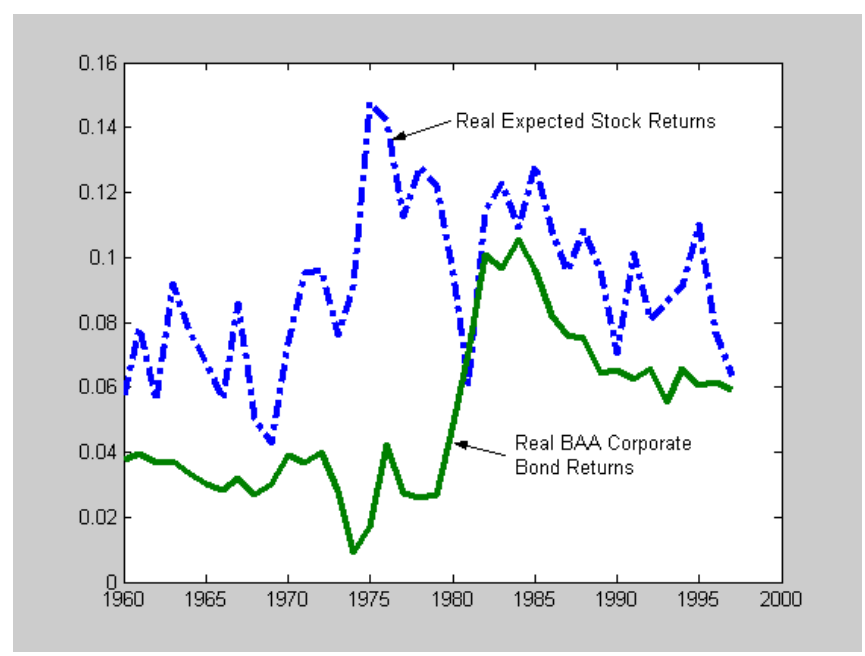

Figure 3: Real Interest Rates. 
rate of nominal output declined (from 6.4 to 6.2 percent). This indicates that the productivity embodied in the new capital used in manufacturing accelerated since 1970. In the hard-to-measure and the non-manufacturing easy-to-measure sectors, however, both the investment intensity and the growth rate of nominal output have been roughly flat. Second, the discount rates (independently of whether we measure them by the real BAA corporate bond rates, by the expected stock returns or by a weighted average of the two) have been higher in the post 1970 period as illustrated by figure 4 . This makes necessary a higher growth rate of embodied productivity to rationalize a given investment rate. As is evident in equation (4), the required increase in the growth rate of $A$ is higher the higher is the investment output ratio. Therefore the increase in the interest rates is going to induce a larger acceleration of embodied productivity in the non-manufacturing easy-to-measure sectors. Next we formalize these intuitions with a more comprehensive model.

\section{The model}

In this section, I extend the previous framework along two dimensions. First, the prices of investment $\left(P_{i t}^{I}\right)$ and interest rates $\left(R_{t}\right)$ are not forced to be constant. Second, the firm now faces a tax system. In addition to a corporate tax $\left(\hat{\tau}_{t}\right)$, firms enjoy an investment tax credit $\left(\hat{\tau}_{i t}^{I}\right)$ and a capital consumption allowance for the assets of vintage $\tau$ at sector $i\left(\hat{\tau}_{i \tau t}^{\delta}\right)$.

The timing of the economy is as follows. Every period $t$, firms produce their sectorial output $\left(Y_{i t}\right)$, then they observe the random variables for period $t+1$, (i.e. $L_{i t+1}, P_{i t+1}$, $P_{i t+1}^{I}, \hat{\tau}_{t+1}, \hat{\tau}_{i t+1}^{I}$ and $\left.\left\{\hat{\tau}_{i \tau t+1}^{\delta}\right\}_{\tau=1}^{t}\right)$ and decide how much output to invest in order to maximize the expected present discounted value of after-tax profits taking as given the stochastic processes that generate the exogenous variables.

Formally, the problem of sector's $i$ representative firm can be expressed as follows:

$$
\underset{\left\{I_{i \tau}\right\}_{\tau=t}^{\infty}}{\operatorname{Max} E_{t} \sum_{\tau=t}^{\infty}\left[\left(\prod_{s=t}^{\tau-1} R_{s}^{-1}\right)\left[\left(1-\hat{\tau}_{\tau}\right)\left(P_{i \tau} Y_{i \tau}-w_{\tau} L_{\tau}\right)-\left(1-\hat{\tau}_{i \tau}^{I}\right) P_{i \tau}^{I} I_{i \tau}+\hat{\tau}_{\tau} \sum_{s=1}^{\tau-1} \hat{\tau}_{i s \tau}^{\delta} P_{i s}^{I} I_{i s}\right]\right]}
$$


s.t $J_{i 0},(2)$ and (1).

To ensure that this problem is well defined, I assume that the following regularity condition holds for each sector along all the possible sample paths:

$$
\lim _{t \rightarrow \infty} \frac{P_{i t} A_{i t}^{\alpha_{i}} Z_{i t}}{P_{i t}^{I} \Pi_{s=1}^{t} R_{s}}=0
$$

The associated first order condition equalizes the marginal cost from investing one additional unit and the expected marginal benefit. It is useful to rewrite this first order condition recursively by applying the law of iterated expectations. ${ }^{13}$

$$
\begin{aligned}
& P_{i t}^{I}\left[1-\hat{\tau}_{i t}^{I}-E_{t}\left[\sum_{v=t}^{\infty}\left(\Pi_{s=t+1}^{v-1} R_{s}^{-1}\right) \hat{\tau}_{v} \hat{\tau}_{i t v}^{\delta}\right]\right] \\
= & A_{i t+1} R_{t}^{-1}\left[\left(1-\hat{\tau}_{t+1}\right) \alpha_{i} P_{i \tau+1} \frac{Y_{i \tau+1}}{J_{i \tau+1}}\right. \\
& \left.+\left(1-\delta_{i}\right) E_{t}\left[\frac{P_{i t+1}^{I}\left[1-\hat{\tau}_{i t+1}^{I}-\left[\sum_{v=t+1}^{\infty}\left(\Pi_{s=t+2}^{v-1} R_{s}^{-1}\right) \hat{\tau}_{v} \hat{\tau}_{i t+1 v}^{\delta}\right]\right]}{A_{i t+2}}\right]\right]
\end{aligned}
$$

A rational expectations equilibrium is a policy function for investment at each sector such that a) the implied sequences of Jelly capital satisfy equation (2), b) the associated sequences of value added at each sector together with the stocks of capital satisfy the sequence of first order conditions (8), and c) expectations are taken rationally.

This equilibrium can be inverted using data on investment, output, taxes and some of the parameters to recover the actual series for embodied and disembodied productiv-

\footnotetext{
${ }^{13}$ Note that this optimality condition can be related to the user cost of capital $\left(c_{i t}\right)$ that now is augmented to incorporate uncertainty about the exogenous variables and, most importantly, embodied productivity of capital. Formally, equation (8) can be rewritten as:

$$
c_{i t}=\alpha_{i} \frac{P_{i t+1} Y_{i t+1}}{J_{i t+1}}
$$
}

where

$$
\begin{aligned}
c_{i t}= & \frac{R_{t} P_{i t}^{I}}{A_{i t+1}\left(1-\hat{\tau}_{t+1}\right)}\left[1-\hat{\tau}_{i t}^{I}-E_{t}\left[\sum_{v=t}^{\infty}\left(\Pi_{s=t+1}^{v-1} R_{s}^{-1}\right) \hat{\tau}_{v} \hat{\tau}_{i t v}^{\delta}\right]\right] \\
& -\left(1-\delta_{i}\right) \frac{E_{t}\left[P_{i t+1}^{I}\left[1-\hat{\tau}_{i t+1}^{I}-\left[\sum_{v=t+1}^{\infty}\left(\Pi_{s=t+2}^{v-1} R_{s}^{-1}\right) \hat{\tau}_{v} \hat{\tau}_{i t+1 v}^{\delta}\right]\right]\right]}{A_{i t+2}\left(1-\hat{\tau}_{t+1}\right)}
\end{aligned}
$$


ity. In the next section, I formalize this idea by building an operator in the space of bounded sequences whose fixed point is the sequence of embodied productivity and use this technology to present the tests of the mismeasurement hypothesis.

\subsection{Identification and mismeasurement}

Let $(S, \rho)$ be the space of bounded infinite sequences $\left\{x_{k}\right\}$ with $x_{k} \in R_{+}, \forall k$, with the supnorm (i.e. $\forall x, y \in S,\|x-y\|=\sup _{k}\left|x_{k}-y_{k}\right|$ ). This is a Banach space (i.e. a complete normed vector space). Let's define the following mapping $(Q(x))$ in this space:

$$
\begin{aligned}
& {[Q(x)](t+1)=\left[P_{i t}^{I}\left[1-\hat{\tau}_{i t}^{I}-E_{t}\left[\sum_{v=t}^{\infty}\left(\Pi_{s=t+1}^{v-1} R_{s}^{-1}\right) \hat{\tau}_{v} \hat{\tau}_{i t v}^{\delta}\right]\right] R_{t}\right]} \\
& {\left[\left(1-\hat{\tau}_{t+1}\right) \alpha_{i} P_{i t+1} \frac{Y_{i t+1}}{J_{i 0}\left(1-\delta_{i}\right)^{t+1}+\sum_{v=0}^{\tau} I_{i \tau-v} x_{\tau+1-v}\left(1-\delta_{i}\right)^{\tau-v}}\right.} \\
& \left.+\left(1-\delta_{i}\right) E_{t}\left[\frac{P_{i t+1}^{I}\left[1-\hat{\tau}_{i t+1}^{I}-\left[\sum_{v=t+1}^{\infty}\left(\Pi_{s=t+2}^{v-1} R_{s}^{-1}\right) \hat{\tau}_{v} \hat{\tau}_{i t+1 v}^{\delta}\right]\right]}{x_{t+2}}\right]\right]^{-1}, \forall t
\end{aligned}
$$

where the sequences of prices, output, investment, taxes, interest rates and the depreciation rate and capital share are fixed, and the expectations are taken rationally by agents that know their distribution. This mapping is an operator because if $x \in S$ so does $Q(x)$.

To simplify the notation in what follows, let's denote $P_{i t}^{I}\left[\left[1-\hat{\tau}_{i t}^{I}-E_{t}\left[\sum_{v=t}^{\infty}\left(\Pi_{s=t+1}^{v-1} R_{s}^{-1}\right) \hat{\tau}_{v} \hat{\tau}_{i t v}^{\delta}\right]\right]\right]$ by $\hat{P}_{i t}^{I}$ and let's define $J_{i t+1}^{q}$ as $J_{i 0}\left(1-\delta_{i}\right)^{t+1}+\sum_{\tau=0}^{t} I_{i t-\tau+1}\left(1-\delta_{i}\right)^{\tau} q_{t-\tau+1}$ for any $q \in S$.

I impose three restrictions on the parameters and stochastic processes that govern the variables that define the operator $Q$. The first two conditions are sufficient (but not necessary) for the operator $Q$ to be a contraction mapping. Condition 3 restricts the stochastic process that governs the ratio $\hat{P}_{i t}^{I} / A_{i t+1}$ and is necessary to derive the neutrality results.

Condition 1: Let $\bar{I}_{i t} \equiv \sup _{0 \leq \tau \leq t} I_{i \tau}$. Then, $\sup _{t \in[0, \infty)}\left[\frac{\hat{P}_{i t}^{I} R_{t} \bar{I}_{i t}\left(1-\delta_{i}^{t+1}\right)}{\delta_{i} \alpha_{i}\left(1-\hat{\tau}_{t}\right) P_{i t} Y_{i t}}\right] \leq 1$. 
Condition 2: $\frac{\hat{P}_{i t}^{I} R_{t} E_{t}\left(\hat{P}_{i t+1}^{I} /\left(x_{t+2}\left(x_{t+2}+a\right)\right)\right)}{\left(1-\delta_{i}\right) E_{t}\left[\frac{\hat{P}_{i t+1}^{I}}{x_{t+2}+a}\right] E_{t}\left[\frac{\hat{P}_{i t+1}^{I}}{x_{t+2}}\right]}<1, \forall t, i, a>0, \Omega_{t}$, where $\Omega_{t}$ is the information set as of time $t$.

Let $\left.E_{t}\left[X_{t+1}\right\rfloor V_{t}\right]$ denote the expected value of $X_{t+1}$ as of $t$ without conditioning on the value of variable $V_{t}$.

Condition 3: $\left.\left.\left.E_{t}\left[\frac{\hat{P}_{i t+1}^{I}}{x_{t+2}}\right\rfloor\left\{P_{i \tau}^{I}\right\}_{\tau=0}^{t}\right]=E_{t}\left[\frac{\hat{P}_{i t+1}^{I}}{x_{t+2}}\right\rfloor\left\{P_{i \tau}\right\}_{\tau=0}^{t}\right]=E_{t}\left[\frac{\hat{P}_{i t+1}^{I}}{x_{t+2}}\right]=E_{t}\left[\frac{\hat{P}_{i t+1}^{I}}{x_{t+2}}\right\rfloor\left\{Z_{i \tau}\right\}_{\tau=0}^{t}\right]$.

Lemma 1: If conditions 1 and 2 hold, $Q: S \rightarrow S$ is a contraction mapping.

Proof: See Appendix.

Since $S$ is a complete metric space, and $Q: S \rightarrow S$ is a contraction mapping with modulus $\beta$, we can apply the Contraction Mapping Theorem to derive proposition 1.

Proposition 1: a) (Existence and Uniqueness) $Q$ has exactly one fixed point, $A$, in $S$.

b) For any $A^{0} \in S,\left\|Q^{n}\left(A^{0}\right)-A\right\| \leq \beta^{n}\left\|A^{0}-A\right\|, n=0,1,2, \ldots$

Part b) of this proposition implies that for any initial guess of the sequence of embodied productivity, the iteration of the operator $Q$ will converge to the fixed point (i.e. the true sequence of embodied productivity). Moreover, from part a), this fixed point is unique. The following three results follow from the proposition.

Corollary 1: (Identification) If the third equality in condition 3 holds, the series of embodied productivity can be identified following the algorithm described by proposition 1.

This is possible because all the variables needed to build the mapping $Q$ are observable, and in particular, $Q$ is independent of the sequence of disembodied productivity $\left(\left\{Z_{i t}\right\}\right)$.

Corollary 2: (Neutrality to $P_{i t}$ ) If nominal output in sector $i$ (i.e. $P_{i t} Y_{i t}$ ) is properly measured and the second and third equalities in condition 3 hold, the series of embodied productivity identified using the algorithm described in proposition 1 are neutral to any mismeasurement of the price deflator at sector $i$.

This result follows from the fact that the operator $Q$ is built only using nominal variables. The economic intuition is quite transparent from equation (8). The Cobb-Douglas 
production function implies that the marginal product of capital is linear in value added; perfect competition, implies that firms take as given the output price in the sector. As a results of these two assumptions, the revenue marginal product of capital is proportional to the nominal output in the sector. Therefore, the series of embodied productivity recovered from the first order conditions are neutral to any mismeasurement of the output price at the sector (i.e. $P_{i t}$ ) as long as the nominal value added is properly measured..$^{14}$

Corollary 3: All the mismeasurement of output shows up in the disembodied component.

Proof: From the production function (1), we can isolate $Z_{i t}$ to identify the series of disembodied productivity.

$$
Z_{i t}=\frac{Y_{i t}}{J_{i t}^{\alpha_{i}} L_{i t}^{1-\alpha_{i}}}
$$

Since the sequence of embodied productivity is neutral to the mismeasurement of the output deflators, so is the series for Jelly capital. Therefore the mismeasurement of real output affects one to one the estimate of disembodied productivity.

The operator $Q$ is built using another price variable, namely, the price of investment goods $\left(P_{i t}^{I}\right)$. It is interesting to consider the effect that the mismeasurement of this price has on the identified series of embodied and disembodied productivity. Proposition 2 gives a sufficient condition for this form of mismeasurement to show up only in the recovered series of embodied productivity.

\section{Proposition 2: (Neutrality of Jelly capital to mismeasurement of investment)} If sectorial nominal investment is properly measured and Condition 3 holds, the mismeasurement of the investment deflator is transmitted one-to-one into the recovered series of embodied productivity $\left\{A_{i t+1}\right\}$. Furthermore, the Jelly capital that results from plugging the recovered series for $\left\{A_{i t+1}\right\}$ into equation (2) is neutral to the mismeasurement of the price of investment.

Proof: Suppose that the nominal investment level is properly measured but that the price of investment reported by the BEA is $\tilde{P}_{i t}^{I}=\zeta P_{i t}^{I}$, where $P_{i t}^{I}$ is the true price level of investment. Then, the BEA level of investment is mismeasured by a factor $1 / \zeta$ (i.e.

\footnotetext{
${ }^{14}$ Perfect Competition is not a critical condition for the renevue marginal product of capital to be linear in nominal output. That still holds for a monopolistic producer, for example, if the demand she faces is isoelastic. In that case the revenue marginal product is augmented by a constant markup.
} 
$\tilde{I}_{i t+1}=\frac{I_{i t+1}}{\zeta}$. To show the result, I construct a series of $A_{i t}$ that satisfies the equilibrium conditions such that the stock of jelly capital is neutral to mismeasurement. That is sufficient to prove the proposition because, from proposition 1 , the sequence of $A_{i t}$ that solves the system is unique.

Ceteris paribus, equation (8) describes a linear relationship between $P_{i t}^{I}$ and $A_{i t+1}$. This means that if the other variables that affect the firm's investment behavior are not altered, the recovered level of embodied productivity $\tilde{A}_{i t+1}$ is mismeasured by the same factor (i.e. $\tilde{A}_{i t+1}=\zeta A_{i t+1}$ ). Indeed, these other variables are not affected. First, since the efficiency of investment is not affected by mismeasurement the capital stock is neutral to mismeasurement. To check this just note that the measured stock of capital is equal to $J_{i t+1}=J_{i t}\left(1-\delta_{i}\right)+\tilde{A}_{i t+1} \tilde{I}_{i t+1}=J_{i t}\left(1-\delta_{i}\right)+\zeta A_{i t+1} \frac{I_{i t+1}}{\zeta}=J_{i t}\left(1-\delta_{i}\right)+A_{i t+1} I_{i t+1}$. Second, From Condition 3, the expectational term in the RHS of (9) is unaffected by the mismeasurement of $P_{t}^{I}$.

Corollary 4, concludes the analysis of the consequences of price mismeasurement on the estimates of embodied and disembodied productivity.

Corollary 4: The recovered sequence of disembodied is neutral to the mismeasurement of investment.

These propositions are useful to investigate the pervasiveness of output mismeasurement. We know from Griliches [1994] and many other sources that there are sectors where output growth is harder to measure and others where it is relatively easy. Interestingly, with the possible exception of finance, the level of nominal value added in all of these sectors is probably quite accurate. It follows from corollary 3 that, if output price mismeasurement is a key determinant of the productivity growth differentials across sectors, we should observe a lower growth rate of the disembodied component in the hard- than in the easy-to-measure sectors. Further, we know from corollary 4 that output price mismeasurement is the only relevant form of mismeasurement for the crosssectional variation in the rate of disembodied productivity growth.

This same line of reasoning may be applied to examine the hypothesis that a worsening of the mismeasurement problems is the cause of the observed productivity slowdown. It also follows from Corollaries 3 and 4 that if mismeasurement problems of the hard-tomeasure sectors have become worse in the last thirty years, we should observe, ceteris 
paribus, a larger decline in the growth rate of disembodied productivity in those sectors that suffer more severe mismeasurement problems.

The next section contains the decomposition of productivity for several US sectors and the tests for the role of output price mismeasurement in the cross-sectional patterns of productivity.

\section{Empirical implementation}

In the development of the identification strategy and the neutrality propositions, I have assumed that we know the level of initial jelly capital (i.e. $J_{i 0}$ ). Obviously, we only know the real capital stock estimated by the BEA which may not be perfectly quality-adjusted. Specifically, $J_{i 0}=\bar{A}_{i 0} K_{i 0}$, where $\bar{A}_{i 0}$ is the unmeasured quality of the initial capital stock. It is easy to verify from equation (9) that the growth rate of $A_{i t}$ is independent of $J_{i 0}$. To show this property of the operator $Q$, note that if we increase $J_{i 0}$ and each element in the sequence $\left\{x_{t}\right\}$ by a factor of $\lambda,[Q(x)]($.$) also increases by \lambda$. This implies that we can identify up to a scale factor the sequence of embodied productivity setting $\bar{A}_{i 0}$ equal to an arbitrary value (say 1 ).

However, for any given sequence of embodied productivity and investment levels, the mismeasurement of the initial average level of embodied productivity $\left(\bar{A}_{i 0}\right)$ biases the average growth rate of jelly capital and of disembodied productivity. Therefore, we must find a way to pin down the value of $\bar{A}_{i 0}$. This is not possible with the current system because we only have $T$ equations to determine $T+1$ unknowns. The additional restriction comes from Nelson [1964]'s approximation of the quality of capital. Nelson shows that the quality adjusted stock of capital can be approximated quite accurately by the following expression:

$$
J_{i t} \simeq\left(1+\gamma_{A i}\right)^{\left(t-G_{i t}\right)} K_{i t}
$$

where $\gamma_{A i}$ is the average growth rate of the quality of capital and $G_{i t}$ denotes the average age of capital at time $t$. This approximation implies that $\bar{A}_{i 0}=\frac{J_{i 0}}{K_{i 0}} \simeq A_{i 1}\left(1+\gamma_{A i}\right)^{-G_{i 0}}$. In this way, we can substitute $J_{i 0}$ by $\bar{A}_{i 0} K_{i 0}$ in the operator $Q($.$) , where \bar{A}_{i 0}$ is approximated by $A_{i 1}\left(\frac{A_{i T+1}}{A_{1}}\right)^{\frac{-G_{i 0}}{T}}$. 
In order to build the operator $Q($.$) , it is necessary to specify a process for \frac{\hat{P}_{i t}^{I}}{A_{i t+1}}$. I have tried several alternatives and the results are robust. For concreteness, I restrict this analysis to the case where $E_{t}\left[\frac{\hat{i}_{i t}^{I}}{A_{i t+1}}\right]=c_{i 0}+c_{i 1} t+c_{i 2} t^{2}+c_{i 3} t^{3}$, where $c_{i 0}, c_{i 1}, c_{i 2}$ and $c_{i 3}$ are sector specific parameters.

\subsection{Data}

The implementation of this algorithm requires data on prices $\left(P_{i t}, P_{i t}^{I}\right)$, nominal interest rates $\left(R_{t}\right)$, real output $\left(Y_{i t}\right)$, investment $\left(I_{i t}\right)$, initial capital stock $\left(K_{i 0}\right)$ and average age of capital $\left(G_{i 0}\right)$, depreciation rates $\left(\delta_{i}\right)$, capital shares $\left(\alpha_{i}\right)$, labor $\left(L_{i t}\right)$ and taxes $\left(\hat{\tau}_{\tau}, \hat{\tau}_{i t}^{I}, \hat{\tau}_{i t v}^{\delta}\right)$. These data are available from various sources for the 2-digit sectors in the US starting in 1960. The measure of labor used in the analysis is adjusted for the quality differentials of the labor force and comes from the Jorgenson KLEM data set. Unfortunately, these series only run through 1997 and this is why I restrict the analysis to the period 1960-1997. The BEA compiles most of the other variables with the exception of the tax rates and the interest rates. The tax rates are computed from data compiled by Jorgenson and Stiroh [2000]. For the interest rates, I explore various alternatives that yield surprisingly similar conclusions. The complete list of rates used includes the returns on BAA corporate bonds, the expected value weighted stock returns where the predicted values are obtained by fitting an ARMA $(1,1)$ process to the historical series since 1960, a weighted average of these two series where the weights are the sector specific debt-asset ratios ${ }^{15}$ and two series of hurdle rates that are 36 and 41 percent higher than this last series. The data necessary to build the discount rate series come from the Federal Reserve, Compustat, Summers [1986] and Bernanke and Campbell [1988].

\subsection{Cross-sectional decomposition}

The first question that we can address with the technology developed so far is whether output mismeasurement is a key determinant of the variation in productivity growth observed across the different sectors. Corollary 3 implies that an important upward bias

\footnotetext{
${ }^{15}$ More exactly, I take the sector specific debt- asset ratios that Bernanke and Campbell [1988] compute from the Compustat data set and then I rescale that for the aggregate debt asset ratios. For finance and agriculture they do not report any sector specific ratio and I use the aggregate ratio.
} 
in the output deflators of the hard-to-measure sectors shows up as a lower growth rate of disembodied productivity in these sectors. In the rest of the section, I report the growth rate of disembodied productivity when these series are identified under various specifications for the discount rate. For comparison purposes, the first column of table 2 contains the average annual growth rate of TFP for each sector in the sample period. This column illustrates that total factor productivity has grown more slowly in the hardto-measure sectors. Indeed, with the exception of trade, TFP has not grown in the last 40 years in the hard-to-measure sectors.

Column 2 reports the average annual growth rate of the disembodied component when the interest rate is given by the rates of the BAA corporate bonds. Two facts stand out from the comparison of columns 1 and 2. First, the gap in the growth rate of $Z$ between the hard-to-measure and the easy-to-measure sectors is much smaller than the differential in the growth rate of TFP. Second, the growth rates of disembodied productivity identified with the BAA bond rates are much higher than the TFP growth rates. As illustrated in the first column of table 3, the counterpart of the high growth rate of $Z$ is that the growth rates of $A$ are negative and large in absolute value. This implies that the BEA grossly overmeasures the efficiency of the new capital used in production. The magnitude of the implied mismeasurement is just too troubling. Most likely, these large negative growth rates of $A$ indicate that the discount rates used by the representative firms are higher than the BAA corporate bond rate. There are several reasons for these higher discount rates. First, issuing debt is just one of the possible ways to finance investment. Firms can also issue equity and then the relevant discount rate considered should be the expected stock returns. Second, many firms -specially the small ones- may face liquidity constraints that increase their effective discount rate. Finally, in an uncertain environment with irreversible investment the relevant discount rate used by the firms is augmented by the value of the option to wait until uncertainty is resolved. In line with these arguments, Summers [1986] reports that, according to a survey conducted on 95 of the top 200 corporations in the Fortune 500, firms evaluate their projects using discount rates that range from 8 to 30 percent with a mean rate of 17 percent. This is about 30 percent higher than the expected rate of return of the US stock markets in 1986 and 36 percent higher than the weighted average between the expected stock returns and the BAA bond rates in 1986.

Columns 3, 4 and 5 of table 2 report the average annual growth rates of $Z$ identified 
when the relevant discount rates are given by the expected stock returns (column 3), the average between the bond and expected stock returns weighted by the debt-asset ratio (column 4) and a hurdle rate that is 36 percent higher than this rate (column 6). There we can see that, as we increase the discount rates, the differential in the growth rate of $Z$ between the hard-to-measure and the easy-to-measure diminishes. Indeed, in column 6 the average growth rate of $Z$ is higher in the hard-to-measure sector and in all three columns the growth rate of $Z$ is higher in the hard-to-measure sectors than in the non-manufacturing-easy-to-measure sectors. The intuition for this finding is quite simple. As the discount rate rises, investment is more costly and to induce the observed investment rates the productivity embodied in new capital must also be higher. The higher is the investment rate, the larger is the revision in the growth rate of $A$ associated with the new discount rates. In figure 1, we observed that the investment rate in the nonmanufacturing-easy-to-measure sectors has been substantially larger than in the rest of the economy. Hence, the growth rate of embodied productivity associated with the new discount rates will be substantially higher in the non-manufacturing-easy-to-measure sectors and, as anticipated in section 2, this effect is sufficiently strong to reverse the cross-sectional pattern for the growth rate of productivity.

Columns 2 to 4 of table 3 report the average growth rate of $A$ associated with the higher discount rates. Though the magnitude of the implied BEA mismeasurement in the efficiency of new capital declines substantially, an annual 3 percent bias for the private economy is probably beyond what is reasonable indicating that the model is still misspecified.

A natural way to correct the misspecification consists on introducing costs of adjustment to new investment. That is going to make more costly the installation of new capital and will boost the required increase in the efficiency of new capital necessary to account for the observed investment rates. I have experimented with several specifications for the adjustment costs and the results are quite robust. The one presented here is based on Bessen [2002]. He assumes that adjustment costs represent a diversion of output. At time $t$

$$
Y_{t}=Y_{t}^{*}\left(1-c_{t}\right)
$$

where $Y$ is actual output, $Y^{*}$ is potential output, and $c$ is the percentage rate of adjustment costs. The absolute magnitude of the adjustment costs in terms of the sector's output is $c_{t} Y_{t}^{*}$. Bessen assumes that $c_{t}$ is equal to $\gamma I_{i t} / K_{i t}$ with an estimate for $\gamma$ of 
about 0.2. This implies that for each additional unit of investment, output is reduced about 0.18 units.

The introduction of the adjustment costs affects the operator $Q(x)$ that now is defined as follows:

$$
\begin{aligned}
& {[Q(x)](t+1)=\left[\hat{P}_{i t}^{I}+\gamma P_{i t} Y_{i t} / K_{i t}\right] R_{t}} \\
& {\left[\left(1-\hat{\tau}_{t+1}\right) \alpha_{i} P_{i t+1} \frac{Y_{i t+1}}{J_{i t+1}^{x}}+\left(1-\delta_{i}\right) E_{t}\left[\frac{\hat{P}_{i t+1}^{I}+\gamma P_{i t+1} Y_{i t+1} / K_{i t+1}}{x_{t+2}}\right]\right]^{-1}, \forall t}
\end{aligned}
$$

From this expression it is quite clear that the biases in the output deflators are not going to affect the identified series of embodied productivity and that corollaries 2 and 3 are still valid. However, the mismeasurement of the investment deflator now affects the uncovered series of disembodied productivity invalidating proposition 2 . This affects the algorithm because now we must identify simultaneously the series for $A$ and the initial level of Jelly capital.

Column 6 of table 2 and column 5 in table 3 report the average growth rate of $Z$ and $A$ once we introduce the adjustment costs with discount rates 36 percent higher than the weighted average between the BAA rates and the expected stock returns. The ranking in the growth rates of $Z$ is very robust. The hard-to-measure sectors have experienced a larger growth rate than the non-manufacturing-easy-to-measure sectors. Basically, with the exception of manufacturing, agriculture and services, the growth rate of disembodied productivity in every hard-to-measure-sector is higher than in every easy-to-measure sector.

The introduction of adjustment costs increases substantially the uncovered growth rates of embodied productivity. Now, the average growth rate for the private economy is -1.61 percent. This implied bias is half of the bias without adjustment costs. Interestingly, this magnitude is very sensitive to the particular parameterizations of the adjustment costs. In columns 7 of table 2 and 6 of table 3 , I report the growth rates of $Z$ and $A$ when the parameter $\gamma$ in the adjustment cost specification is equal to 0.3 and when the interest rates are 41 percent higher than the weighted average between the BAA rates and the expected stock returns. With this new parameterization, the growth rate of $A$ for the private economy is -0.4 percent and the growth rate of Jelly capital is 3.21 percent, higher than the growth rate of physical capital (3.04 percent). 
By trying these various specifications for the discount rates and adjustment costs, we have been able to establish the robustness of the higher growth rate of disembodied productivity in the hard-to-measure sectors than in the non-manufacturing easy-to-measure sectors. This fact is important because corollary 3 showed that the upward bias in the output deflators reduces one for one the growth rate of the disembodied component. Since the hard-to-measure sectors are more susceptible to experience such a bias, this finding implies that factors other than price mismeasurement are more important to explain the observed variation in productivity growth across sectors.

\subsection{Mismeasurement and the productivity slowdown}

Now we turn to the time series dimension and analyze whether a worsening of the mismeasurement problems has caused an artificial productivity slowdown in the BEA measures. In principle, the worsening of the price mismeasurement could come from three channels. First, from a change in the composition of output towards the hardto-measure sectors. Second, from a general worsening of the ability to measure quality improvements that affected both easy- and hard-to-measure sectors. Third, from a worsening of the existing mismeasurement problems in the hard-to-measure sectors. The first channel has been shut down by Sichel [1997] by showing that the compositional change in favor of the hard-to-measure sectors can account for a very minor fraction of the productivity slowdown. Channel number two is also likely to be quite weak. First, the productivity slowdown has been substantially larger in the hard- than in the easy-tomeasure sectors. Moreover, any attempt to put the hard- and easy-to-measure sectors in the same bag can be challenged by the fact that in the former there is no sign of an acceleration in TFP, while in the easy-to-measure sectors the slowdown in the seventies was followed by an impressive recovery during the eighties and nineties. Second, the most important improvements in the BEA measures of the output deflators during the last thirty years have taken place in manufacturing, transportation and communications (Mohr [1992]). In the first, the BEA has introduced new hedonic price indices for an important set of goods (computers, semiconductors, motor vehicles, among others). ${ }^{16}$ In the last two, the BEA has moved to double deflation methods to compute constant-dollar GNP at the industry level. Finally, as argued by Baily and Gordon [1988], the outputs

\footnotetext{
${ }^{16}$ See Moulton [2001] for a description of the expanding role of hedonic methods in the US official statistics.
} 
of the easy-to-measure sector are to a larger extent intermediate goods than those of the hard-to-measure sectors. In this sense, failing to account for the quality improvement of a durable good is not going to help us understand the aggregate productivity slowdown.

The only remaining channel for a worsening of the price mismeasurement problems to explain a large fraction of the slowdown is a within effect in the hard-to-measure sectors. Some authors have noted that indeed, some important quality improvements in the finance, insurance (Baily and Gordon [1988] and Bresnahan [1986]) and health-care (Dranove, Shanley and White [1991]) sectors in the last twenty five years have not been captured by the official statistics. From corollary 3, we know that these mismeasurements of the output deflators pass on completely to the disembodied component. Hence, if the decline in measured productivity growth is the result of a worsening of the mismeasurement problems in the hard-to-measure sectors, we should observe that the disembodied productivity has slowed down more in those sectors than in the sectors where output growth is easy to measure.

Table 4 tests this prediction by computing the increase in the annual growth rate of $Z$ from the period 1960-70 to 1970-1997 for various specifications of the discount rates and adjustment costs described in the previous section. There are two salient facts from this table. First, in all the sectors, there has been a decline in the growth rate of disembodied productivity. Second, for all the various specifications, the decline in disembodied productivity growth has been larger in the easy-to-measure sectors than in the hard-to-measure sectors. Since an increase in the bias in the output deflator of the latter sectors should be reflected in a decline in the growth rate of their disembodied productivity component, table 4 implies that there are other factors substantially more important than the evolution of the output deflators biases to understand the variation across sectors in the size of the productivity slowdown. Moreover, since the only potentially important channel for a worsening of the mismeasurement problems to generate the productivity slowdown is through the decline in disembodied productivity of the hard-to-measure sectors and this has been smaller than in the easy-to-measure, the role of mismeasurement in the slowdown must be quite small. 


\subsection{Robustness to more general production functions}

The key assumption for the neutrality of the embodied component to the mismeasurement of the output deflator is that the production function for the different sectors is Cobb-Douglas. If this is not a good approximation, the mismeasurement of the output prices is going to affect both the embodied and the disembodied components invalidating the neutrality results that supported the mismeasurement tests. Moreover, the operator $Q$ will be misspecified.

Two questions arise at this point. First, is the Cobb-Douglas assumption a sensible one? Second, is it possible to extend the mismeasurement tests to the case where the production function at the sector level is not Cobb-Douglas?

There is a substantial body of literature that tries to estimate production functions. Specifically, the emphasis has been placed on the degree of returns to scale and on the elasticity of substitution between capital and labor. The null hypothesis in all these analysis is the Cobb-Douglas which displays constant returns to scale and a unit elasticity of substitution.

Basu [1997] and Burnside, Eichembaum and Rebelo [1995] among others have shown that the production function for basically every two digit sector (Basu) and for the nonfarm private economy (Burnside, Eichembaum and Rebelo) displays constant returns to scale once we take into account the cyclical variation in the intensity of utilization of capital and labor.

With respect to the elasticity of substitution between capital and labor, Berndt [1976] estimates this parameter assuming a constant elasticity of substitution (CES) production function for the time series of the manufacturing sector. He uses six different econometric specifications that arise from the first order conditions of the firm and finds that the elasticity of substitution is not statistically different from 1 . In a recent paper, Antràs [2001] extends Berndt's analysis to the US private economy and confirms his results. Then, Antràs generalizes the production function by allowing different forms of technological progress. He estimates the equation in levels using OLS, GLS and instrumental variables. He also estimates the model in first differences using OLS and two stage least squares. This amounts to $(5 \times 6)$ thirty estimates of the elasticity of substitution between capital and labor. Out of these thirty, in fifteen cases he cannot reject the null that the 
elasticity of substitution is statistically different from 1 at the five percent significance level. In two cases he can reject with a point estimate higher than 1, and in thirteen cases he rejects with a point estimate smaller than one. The odds of rejecting seem more favorable to the Cobb-Douglas case when we restrict attention to the instrumented regressions. There, out of twelve cases, only in three he can reject the null of unit elasticity, always with point estimates lower than 1 . This indicates that the Cobb-Douglas is a more than reasonable assumption and that the clear alternative hypothesis is that the elasticity of substitution between capital and labor is less than unity.

Now, suppose that we adopt the alternative assumption that Jelly capital and labor are complements. Can we infer anything about the role of mismeasurement in productivity growth from the growth rate of the disembodied component?

The answer to this question depends on whether the effect of the deflator bias on the growth rate of $Z$ becomes larger when we increase the complementarity between $J$ and $L$. If this is the case, a higher growth rate of disembodied productivity in the hard-tomeasure sectors implies, a fortiori, that mismeasurement is not an important determinant of the variation in productivity growth across sectors.

To investigate this avenue, consider the following CES production function:

$$
Y_{i t}=\left[\alpha J_{i t}^{\psi}+(1-\alpha)\left(Z_{i t} L_{i t}\right)^{\psi}\right]^{1 / \psi}
$$

where the elasticity of substitution between $J$ and $L$ is equal to $\psi /(1-\psi)$.

The new operator $Q$ is defined as:

$$
\begin{aligned}
& {[Q(x)](t+1)=\hat{P}_{i t}^{I} R_{t}} \\
& {\left[\left(1-\hat{\tau}_{t+1}\right) \alpha_{i} P_{i t+1}\left(\frac{Y_{i t+1}}{J_{i t+1}^{x}}\right)^{1-\psi}+\left(1-\delta_{i}\right) E_{t}\left[\frac{\hat{P}_{i t+1}^{I}}{x_{t+2}}\right]\right]^{-1}, \forall t}
\end{aligned}
$$

Once the sequence of $A_{i t}$ is recovered from the data, $Z_{i t}$ is given by the following expression:

$$
Z_{i t}=\left[\frac{Y_{i t}^{\psi}-\alpha J_{i t}^{\psi}}{(1-\alpha) L_{i t}^{\psi}}\right]^{\frac{1}{\psi}}
$$

To explore the interaction between the elasticity of substitution and the bias in the output deflator, I create artificial series of real output that result from introducing a 
bias in the output deflator keeping unchanged nominal output. Using these artificial series, I identify the associated series of disembodied productivity for several degrees of mismeasurement and elasticities of substitution. Table 5 contains the results from this exercise for the private non-residential sector when the interest rates are equal to the average of the expected stock returns and the BAA corporate bond rates weighted by the debt-asset ratio. The conclusions are robust to all the sectors and specifications for the interest rates and adjustment costs. In the first row, I report the average annual growth rate of $Z$ when capital and labor are unit elastic for several biases in the output deflator that range from none (column 1) to an annual upward bias of 1.5 percent. As indicated by corollary 3 , there is a one to one effect of the bias on the growth rate of $Z$. The question that we are trying to answer is whether this impact on the growth rate of $Z$ is larger or smaller as we reduce the elasticity of substitution between capital and labor. In rows 2 to 7 , I report the growth rate of $Z$ when capital and labor have a higher degree of complementarity. It is quite clear that the lower is the elasticity of substitution between $J$ and $L$, the higher is the effect of mismeasurement on the growth rate of the recovered $Z$. This can be observed in panel B of table 5 where I subtract the growth rates of $Z$ for the artificial biases from the "unbiased" series.

This exercise implies that, if the elasticity of substitution between capital and labor is less than 1 and the hard-to-measure sectors' output deflator are upwardly biased, we should observe, ceteris paribus, an even larger differential in the growth rate of $Z$ in favor of the easy-to-measure sectors.

This prediction of the mismeasurement hypothesis is tested in table 6 that contains the annual growth rate of $Z$ for the various sectors and elasticities of substitution. Here, for brevity, I only report the results for the specification where the interest rates are given by the average of the expected stock returns and the BAA corporate bond rates weighted by the debt-asset ratio. By comparing column 1 with the other columns we can observe that the gap in the growth rate of disembodied productivity increases when we reduce the elasticity of substitution between capital and labor. ${ }^{17}$ This may seem shocking since

\footnotetext{
${ }^{17}$ In finance, the sequence of $Z$ cannot be recovered when the elasticity of substitution between $J$ and $L$ is 0.9 or lower because the numerator in the brackets of expression (13) becomes negative. The range of feasible values of $\psi$ increases when we increase the interest rate. In terms of the cross-sectional comparison of the growth rate of disembodied productivity, the exclusion of finance does not affect the fact that as we reduce the elasticity of substitution between capital and labor, the difference in favor of the hard-to-measure sectors increases. One could argue that probably the elasticity differs across sectors in such a way that this inequality can be reversed. This however seems quite unlikely
} 
I have just concluded that by reducing the elasticity we accentuate the effect of the bias on the disembodied component. The reconciliation of these two facts comes from a second effect that the elasticity of substitution has on the operator $Q$, namely that the complementarity between $J$ and $L$ introduces a higher curvature in the marginal product of capital. In sectors that invest a lot, $A$ must grow very much to induce the observed investment rates. As a result, the lower $\psi$ also amplifies the differences in the growth rate of embodied productivity. This second effect dominates the first one enhancing the differential in the growth rate of $Z$ in favor of the hard-to-measure sectors.

The same exercise can be conducted to evaluate whether the conclusion on the role of mismeasurement on the productivity slowdown can be extended to production functions where capital and labor are complements. As in the cross section, it is the case that, when reducing the elasticity of substitution between capital and labor, the slowdown in disembodied productivity is even higher in the easy-to-measure sectors relative to the hard-to-measure sectors. Hence, the conclusions of section 4.2 are also robust to these more general production functions.

\section{Conclusions}

This paper has tried to assess the importance of mismeasurement for productivity growth. If firms observe accurately the relevant prices, we can invert the firm's investment decision to identify the different components of productivity growth. The approach proposed in this paper consists in inspecting how mismeasurement affects the embodied and disembodied components and comparing the implications of the mismeasurement hypothesis with the cross-section and time series patterns of these components across the 2-digit sectors. I have shown that both when the production function is CobbDouglas and CES with inelastic substitution between capital and labor, an upward bias in the output deflator should reduce the growth rate of disembodied productivity. The decomposition of productivity growth into the embodied and the disembodied components has illustrated that both the growth rate and the increase since 1970 in the growth

because, for any vector of elasticities of substitution, the growth rate of disembodied productivity in the non-manufacturing easy-to-measure sectors is lower than in the hard-to-measure sectors. This statement holds also for all the easy-to-measure sectors (i.e. including manufacturing) if the elasticity of substitution is less than unity. 
rate of disembodied productivity have been higher in the sectors that are susceptible of suffering biases in the output deflator. These findings indicate that output price mismeasurement is not a key element in the observed variation across sectors or in the time series evolution of productivity growth. Future research should identify the real factors that determine the variation across sectors in the productivity patterns. The analysis conducted in this paper indicates that there is an important payoff from building and testing new theories on the determinants of disembodied productivity growth. 


\section{A Appendix}

In this appendix I prove that under conditions 1 and 2, the operator $Q$ defined in equation (9) is a contraction mapping.

Condition 1: Let $\bar{I}_{i t} \equiv \sup _{0 \leq \tau \leq t} I_{i \tau}$. Then, $\sup _{t \in[0, \infty)}\left[\frac{\hat{P}_{i t}^{I} R_{t} \bar{I}_{i t}\left(1-\delta_{i}^{t+1}\right)}{\delta_{i} \alpha_{i}\left(1-\hat{\tau}_{t}\right) P_{i t} Y_{i t}}\right] \leq 1$.

Condition 2: $\frac{\hat{P}_{i t}^{I} R_{t} E_{t}\left(\hat{P}_{i t+1}^{I} /\left(x_{t+2}\left(x_{t+2}+a\right)\right)\right)}{\left(1-\delta_{i}\right) E_{t}\left[\frac{\hat{P}_{i t+1}^{I}}{x_{t+2}+a}\right] E_{t}\left[\frac{\hat{P}_{i t+1}^{I}}{x_{t+2}}\right]}<1, \forall t, i, a>0, \Omega_{t}$, where $\Omega_{t}$ is the information set as of time $t$.

Lemma 1: If conditions 1 and 2 hold, $Q: S \rightarrow S$ is a contraction mapping.

Proof: Blackwell's Theorem gives two conditions that are sufficient for $Q$ to be a contraction, these are monotonicity and discounting (Stokey, Lucas and Prescott [1989], p. 54). Formally, monotonicity implies that $\forall x, y \in S$, and such that $x_{t} \leq y_{t} \forall t$, $Q\left(x_{t}\right) \leq Q\left(y_{t}\right)$. Discounting is satisfied if $\forall x \in S, a>0$, and $t, \exists \beta \in(0,1)$ such that

$$
Q\left(x_{t}+a\right) \leq Q\left(x_{t}\right)+\beta a
$$

It's very straightforward to verify that $Q$ is monotonically increasing in $x$, therefore it satisfies the monotonicity condition.

Discounting holds iff $\forall x \in S, a>0$, and $t, \exists \beta \in(0,1)$ such that:

$$
\frac{Q\left(x_{t}+a\right)-Q\left(x_{t}\right)}{a} \leq \beta \text {. }
$$

Substituting (9) into (14), we obtain that

$$
\begin{aligned}
\frac{Q\left(x_{t}+a\right)-Q\left(x_{t}\right)}{a}= & \frac{\hat{P}_{i t}^{I} R_{t}}{a}\left[\left(1-\hat{\tau}_{\tau+1}\right) \alpha_{i} P_{i t+1} Y_{i t+1}\left(\frac{1}{J_{i t+1}^{x}}-\frac{1}{J_{i t+1}^{x+a}}\right)\right. \\
& \left.+\left(1-\delta_{i}\right)\left[E_{t}\left(\frac{\hat{P}_{i t+1}^{I}}{x_{t+2}}\right)-E_{t}\left(\frac{\hat{P}_{i t+1}^{I}}{x_{t+2}+a}\right)\right]\right] \\
& {\left[\frac{\left[\left(1-\hat{\tau}_{\tau+1}\right) \alpha_{i} P_{i t+1} Y_{i t+1}\right]^{2}}{J_{i t+1}^{x} J_{i t+1}^{x+a}}+\left(1-\delta_{i}\right)^{2} E_{t}\left[\frac{\hat{P}_{i t+1}^{I}}{x_{t+2}}\right] E_{t}\left[\frac{\hat{P}_{i t+1}^{I}}{\left(x_{t+2}+a\right)}\right]\right.} \\
& \left(1-\delta_{i}\right)\left(1-\hat{\tau}_{\tau+1}\right) \alpha_{i} P_{i t+1} Y_{i t+1}
\end{aligned}
$$




$$
\left.\left[\frac{1}{J_{i t+1}^{x+a}} E_{t}\left[\frac{\hat{P}_{i t+1}^{I}}{x_{t+2}}\right]+\frac{1}{J_{i t+1}^{x}} E_{t}\left[\frac{\hat{P}_{i t+1}^{I}}{\left(x_{t+2}+a\right)}\right]\right]\right]^{-1}
$$

It is easy to check that the right hand side of this equation can be expressed as:

$$
\frac{1}{a}\left[\varsigma_{1} \frac{\hat{P}_{i t}^{I} R_{t}\left[J_{i t+1}^{x+a}-J_{i t+1}^{x}\right]}{\alpha_{i}\left(1-\hat{\tau}_{t}\right) P_{i t} Y_{i t}}+\varsigma_{2} \frac{a \hat{P}_{i t}^{I} R_{t} E_{t}\left(\hat{P}_{i t+1}^{I} /\left(x_{t+2}\left(x_{t+2}+a\right)\right)\right)}{\left(1-\delta_{i}\right) E_{t}\left[\frac{\hat{P}_{i t+1}^{I}}{x_{t+2}+a}\right] E_{t}\left[\frac{\hat{P}_{i t+1}^{I}}{x_{t+2}}\right]}\right]
$$

where $\varsigma_{1}$ and $\varsigma_{2}>0$ and $\varsigma_{1}+\varsigma_{2}<1$.

Now note that $J_{i t+1}^{x+a}=\left(1-\delta_{i}\right)^{t+1} K_{0}+\sum_{s=0}^{t} I_{s}\left(1-\delta_{i}\right)^{t-s}\left(x_{s+1}+a\right)$ and that $J_{i t+1}^{x}=$ $\left(1-\delta_{i}\right)^{t+1} K_{0}+\sum_{s=0}^{t} I_{s}\left(1-\delta_{i}\right)^{t-s} x_{s+1}$, therefore

$$
\begin{aligned}
\frac{Q\left(x_{t}+a\right)-Q\left(x_{t}\right)}{a}= & \varsigma_{1} \frac{\hat{P}_{i t}^{I} R_{t} \sum_{s=0}^{t} I_{s}\left(1-\delta_{i}\right)^{t-s}}{\alpha_{i}\left(1-\hat{\tau}_{t}\right) P_{i t} Y_{i t}}+\varsigma_{2} \frac{\hat{P}_{i t}^{I} R_{t} E_{t}\left(\hat{P}_{i t+1}^{I} /\left(x_{t+2}\left(x_{t+2}+a\right)\right)\right)}{\left(1-\delta_{i}\right) E_{t}\left[\frac{\hat{P}_{i t+1}^{I}}{x_{t+2}+a}\right] E_{t}\left[\frac{\hat{P}_{i t+1}^{I}}{x_{t+2}}\right]} \\
\leq & \varsigma_{1} \frac{\hat{P}_{i t}^{I} R_{t} \sum_{s=0}^{t}\left(1-\delta_{i}\right)^{t-s} \sup _{0 \leq v \leq t} I_{v}}{\alpha_{i}\left(1-\hat{\tau}_{t}\right) P_{i t} Y_{i t}}+\varsigma_{2} \frac{\hat{P}_{i t}^{I} R_{t} E_{t}\left(\hat{P}_{i t+1}^{I} /\left(x_{t+2}\left(x_{t+2}+a\right)\right)\right)}{\left(1-\delta_{i}\right) E_{t}\left[\frac{\hat{P}_{i t+1}^{I}}{x_{t+2}+a}\right] E_{t}\left[\frac{\left.\hat{P}_{i t+1}^{I}\right]}{x_{t+2}}\right]} \\
\leq & \varsigma_{1} \sup _{\tau}\left(\frac{\hat{P}_{i \tau}^{I} R_{\tau} \sum_{s=0}^{\tau}\left(1-\delta_{i}\right)^{\tau-s} \sup _{0 \leq v \leq \tau} I_{v}}{\alpha_{i}\left(1-\hat{\tau}_{\tau}\right) P_{i \tau} Y_{i \tau}}\right)+ \\
& \varsigma_{2} \sup _{\tau, a>0}\left(\frac{\hat{P}_{i \tau}^{I} R_{\tau} E_{\tau}\left(\hat{P}_{i \tau+1}^{I} /\left(x_{\tau+2}\left(x_{\tau+2}+a\right)\right)\right)}{\left(1-\delta_{i}\right) E_{\tau}\left[\frac{\left.\hat{P}_{i \tau+1}^{I}\right] E_{\tau+2}\left[\frac{\hat{P}_{i \tau+1}^{I}}{x_{\tau+2}}\right]}{x_{\tau+2}+a}\right)}\right.
\end{aligned}
$$

But conditions 1 and 2 imply that the sup terms are strictly lower than 1 , therefore $\exists \beta<1$ such that, $\frac{Q\left(x_{t}+a\right)-Q\left(x_{t}\right)}{a}<\beta, \forall t, a>0$ and $x \in S$. 


\section{References}

[1] Antràs, P. [2001], "Is the U.S. Aggregate Production Function Cobb-Douglas? New Estimates of the Elasticity of Substitution" mimeo MIT

[2] Baily, M. and R. Gordon [1988], "The Productivity Slowdown, Measurement Issues, and the Explosion of Computer Power",Brookings Papers on Economic Activity, XIX(II), 347-420.

[3] Berndt, E. [1973], "Reconciling Alternative Estimates of the Elasticity of Substitution" Review of Economics and Statistics, 58 No. 1, 59-68.

[4] Bessen, J. [2002], "Technology Adoption Costs and Productivity Growth: The Transition to Information Technology" Review of Economic Dynamics Vol. 5, No 2 , pp 443-469.

[5] Bresnahan, T. [1986], "Measuring the Spillovers from Technical Advance: Mainframe Computers in Financial Services", The American economic Review, Vol. 76, 4 (September), 742-755.

[6] Costa, D. [2001], "Estimating Real Income in the United States from 1888 to 1994: Correcting CPI Bias Using Engel Curves" Journal of political economy Vol. 109, No. 6, pp. 1288-1310.

[7] Griliches, Z. [1992], "Introduction", in Z. Griliches, ed., Output Measurement in the Service Sectors, NBER Studies on Income and Wealth, Vol. 56. Chicago, University of Chicago Press, pp. 1-22.

[8] Griliches, Z. [1994], "Productivity, R\&D and the Data Constraint" American Economic Review Vol. 84, No. 1, pp. 1-23.

[9] Dranove, Shanley, and White [1991], "Does the Consumer Price Index Overstate Hospital Price Inflation?" Medical Care, XXIX, August, 690-96.

[10] Hamilton, B. [2001], "Using Engel's Law to estimate CPI Bias" American Economic Review, Vol. 91, pp. 619-30.

[11] Hobijn, B. [1999], "Identifying Sources of Growth" mimeo NYU. 
[12] Hulten, C. [2002], "Price Hedonics: A Critical Review" mimeo, University of Maryland.

[13] Mohr, M. [1992], "Recent and Planned Improvements in the Measurement and Deflation of Services Outputs and Inputs in BEA's Gross Product Originating Estimates", in Z. Griliches, ed., Output Measurement in the Service Sectors, NBER Studies on Income and Wealth, Vol. 56. Chicago, University of Chicago Press, pp.25-68.

[14] Moulton, B. [2001], "The Expanding Role of Hedonic Methods in the Official Statistics of the United States" BEA, mimeo.

[15] Nelson, R. [1964], "Aggregate Production Functions and Medium-Range Growth Projections" American Economic Review Vol. 54, 5 (September), p. 575-606.

[16] Sichel [1997], "The Productivity Slowdown: Is a Growing Unmeasurable Sector the Culprit?" Review of Economics and Statistics, 79(3), pages 367-70.

[17] Stokey, N. and R. Lucas with E. Prescott [1989], Recursive Methods in Economic Dynamics Harvard University Press, Cambridge.

[18] Solow, R. [1959], "Investment and Technical Change" in Mathematical Methods in the Social Sciences, Stanford.

[19] Triplett, J.[1997], "Measuring Consumption: The Post-1973 Slowdown and the Research Issues" Federal Reserve Bank of Saint Louis Review. 79, pp. 9-42." 
Table 1. Productivity growth and increase in productivity growth from the periods $1960-70$ to $1970-97$

\begin{tabular}{c|cc}
\hline \multicolumn{1}{c|}{ Variable } & TFP & $\Delta$ TFP \\
\hline Private Non-Residential & 1.15 & -1.21 \\
Easy-to-Measure & $\mathbf{2 . 0 1}$ & $-\mathbf{0 . 8 5}$ \\
Utilities & 0.58 & -4.21 \\
Agriculture & 2.8 & 0.76 \\
Mining & -0.44 & -3.15 \\
Communications & 2.24 & -1.48 \\
Transportation & 1.78 & -0.33 \\
Non-manuf- & & \\
Easy-to-measure & $\mathbf{1 . 4 9}$ & -1.66 \\
Manufacturing & 2.34 & -0.34 \\
Hard-to-Measure & $\mathbf{0 . 1 7}$ & -1.35 \\
Construction & -0.26 & -0.4 \\
Wholesale Trade & 2.1 & -0.66 \\
Retail Trade & 0.96 & -1.41 \\
Finance & -0.73 & -1.72 \\
Services & -0.22 & -1.57 \\
\hline
\end{tabular}

Column 1: Average annual percentage growth rate of total factor productivity in each sector. Column 2: Increase in the average annual percentage growth rate of total factor productivity from the period 1960-70 to 1970-97. Source: BEA and author's calculations. 
Table 2: Percentage annual growth rate of $Z$ between 1960 and 1997.

\begin{tabular}{|c|c|c|c|c|c|c|c|}
\hline Variable & TFP & Z & Z & $Z$ & Z & Z & Z \\
\hline Interest rates & & $\begin{array}{l}\text { BAA } \\
\text { bonds }\end{array}$ & $\begin{array}{l}\text { Expected } \\
\text { stock returns }\end{array}$ & $\begin{array}{l}\text { Weighted } \\
\text { average }\end{array}$ & $\begin{array}{l}\text { Hurdle } \\
\text { rate }\end{array}$ & $\begin{array}{l}\text { Hurdle } \\
\text { rate }\end{array}$ & $\begin{array}{c}\text { High } \\
\text { Hurdle rate }\end{array}$ \\
\hline Adjustment costs & & - & - & - & - & low & High \\
\hline Private Non-Residential & 1.15 & 3.35 & 2.74 & 2.86 & 2.04 & 1.61 & 1.12 \\
\hline Easy-to-Measure & 2.01 & 3.60 & 2.71 & 2.90 & 1.69 & 1.26 & 0.67 \\
\hline Utilities & 0.58 & 2.8 & 1.06 & 1.6 & -0.54 & -0.41 & -0.89 \\
\hline Agriculture & 2.8 & 4.55 & 3.31 & 3.54 & 1.91 & 1.65 & 1.03 \\
\hline Mining & -0.44 & 2.56 & 0.68 & 1.01 & -1.82 & -1.6 & -2.3 \\
\hline Communications & 2.24 & 3 & 1.94 & 2.26 & 0.78 & 0.77 & 0.37 \\
\hline $\begin{array}{l}\text { Transportation } \\
\text { Non-manuf- }\end{array}$ & 1.78 & 3.81 & 2.03 & 2.52 & 0.08 & -0.14 & -0.98 \\
\hline Easy-to-measure & 1.49 & 3.33 & 1.83 & 2.21 & 0.17 & 0.14 & -0.45 \\
\hline Manufacturing & 2.34 & 3.78 & 3.26 & 3.34 & 2.65 & 1.97 & 1.38 \\
\hline Hard-to-Measure & 0.17 & 2.99 & 2.50 & 2.60 & 1.97 & 1.20 & 0.52 \\
\hline Construction & -0.26 & 3.11 & 2.81 & 2.87 & 2.51 & 1.34 & 0.45 \\
\hline Wholesale Trade & 2.1 & 4.44 & 4.06 & 4.14 & 3.52 & 1.88 & 0.62 \\
\hline Retail Trade & 0.96 & 2.16 & 1.79 & 1.85 & 1.34 & 0.62 & 0.03 \\
\hline Finance & -0.73 & 3.89 & 3.17 & 3.31 & 2.53 & 2.34 & 1.99 \\
\hline Services & -0.22 & 1.67 & 1.25 & 1.33 & 0.7 & -0.2 & -0.96 \\
\hline
\end{tabular}

Average growth rate of TFP (first column) and disembodied productivity (second to seventh columns) during the period 1960-97 for the different sectors in the private non-residential economy. The growth rate of disembodied productivity is computed as the residual in labor productivity after taking into account the contribution of Jelly capital (equation (11)). To identify embodied productivity, I use the following parameterizations for the discount rate: the rate of return on BAA bonds (column 2), the expected stock returns (column 3), the average between the returns to the BAA corporate bonds and the expected stock returns weighted by the sector specific debt-asset ratio (column 4), a hurdle rate that is 36 percent higher than the rate used in column 4 (columns 5 and 6), and a hurdle rate that is 41 percent higher than the rate used in column 4 (column 7). In columns 6 and 7, I introduce adjustment costs as in Bessen [2002] with a coefficient $\gamma$ of 0.2 in column 6 and 0.3 in column 7 . 
Table 3: Percentage annual growth rate of A between 1960 and 1997.

\begin{tabular}{|c|c|c|c|c|c|c|}
\hline Variable & $\mathrm{A}$ & $\mathrm{A}$ & $\mathrm{A}$ & $\mathrm{A}$ & $\mathrm{A}$ & $A$ \\
\hline Interest rates & $\begin{array}{l}\text { BAA } \\
\text { bonds }\end{array}$ & $\begin{array}{c}\text { Expected } \\
\text { stock returns }\end{array}$ & $\begin{array}{l}\text { Weighted } \\
\text { average }\end{array}$ & $\begin{array}{l}\text { Hurdle } \\
\text { rate }\end{array}$ & $\begin{array}{l}\text { Hurdle } \\
\text { rate }\end{array}$ & $\begin{array}{l}\text { High } \\
\text { Hurdle rate }\end{array}$ \\
\hline Adjustment costs & - & - & - & - & low & High \\
\hline Private Non-Residential & -6.09 & -4.5 & -4.77 & -3.35 & -1.61 & -0.4 \\
\hline Easy-to-Measure & -4.72 & -1.08 & -2.85 & -0.71 & 1.45 & 3.04 \\
\hline Utilities & -4.3 & -1.08 & -1.91 & 0.84 & 1.44 & 2.21 \\
\hline Agriculture & -3.3 & -1.15 & -1.51 & 0.58 & 1.68 & 2.7 \\
\hline Mining & -4.48 & -1.15 & -1.64 & 1.41 & 2.18 & 3.12 \\
\hline Communications & -2.11 & 0.86 & 0.12 & 2.83 & 3.72 & 4.67 \\
\hline $\begin{array}{l}\text { Transportation } \\
\text { Non-manuf- }\end{array}$ & -3.81 & -0.81 & -1.56 & 1.38 & 2.93 & 4.32 \\
\hline Easy-to-measure & -0.70 & -0.11 & -0.24 & 0.30 & 0.50 & 0.70 \\
\hline Manufacturing & -5.51 & -3.65 & -3.9 & -2.11 & 0.8 & 2.75 \\
\hline Hard-to-Measure & -8.29 & -6.88 & -7.11 & -5.82 & -1.80 & 1.70 \\
\hline Construction & -14.22 & -13.2 & -13.38 & -12.5 & -7.02 & -3.77 \\
\hline Wholesale Trade & -8.99 & -7.56 & -7.83 & -6.25 & 1.22 & 6.06 \\
\hline Retail Trade & -6.52 & -4.52 & -4.8 & -2.84 & 1.54 & -4.31 \\
\hline Finance & -6.75 & -5.84 & -5.99 & -5.36 & -4.79 & 3.84 \\
\hline Services & -8.97 & -7.24 & -7.54 & -5.93 & -0.36 & 3.06 \\
\hline
\end{tabular}

Average growth rate of embodied productivity during the period 1960-97 for the different sectors in the private nonresidential economy. To identify embodied productivity, I use the following parameterizations for the discount rate: the rate of return on BAA bonds (column 1), the expected stock returns (column 2), the average between the returns to the BAA corporate bonds and the expected stock returns weighted by the sector specific debt-asset ratio (column 3), a hurdle rate that is 36 percent higher than the rate used in column 3 (columns 4 and 5), and a hurdle rate that is 41 percent higher than the rate used in column 3 (column 6). In columns 5 and 6, I introduce adjustment costs as in Bessen [2002] with a coefficient $\gamma$ of 0.2 in column 5 and 0.3 in column 6. 
Table 4: Increase in the annual growth rate between the periods 1960-70 and 1970-97.

\begin{tabular}{|c|c|c|c|c|c|c|}
\hline Variable & TFP & Z & Z & Z & Z & Z \\
\hline Interest rates & & $\begin{array}{l}\text { BAA } \\
\text { bonds }\end{array}$ & $\begin{array}{c}\text { Expected } \\
\text { stock returns }\end{array}$ & $\begin{array}{l}\text { Weighted } \\
\text { average }\end{array}$ & $\begin{array}{l}\text { Hurdle } \\
\text { rate }\end{array}$ & $\begin{array}{c}\text { High } \\
\text { Hurdle rate }\end{array}$ \\
\hline Adjustment costs & & - & - & - & low & High \\
\hline Private Non-Residential & -1.21 & -1.08 & -1.11 & -1.09 & -1.63 & -1.8 \\
\hline Easy-to-Measure & -0.85 & -1.33 & -1.37 & -1.35 & -1.85 & -1.94 \\
\hline Utilities & -4.21 & -4.69 & -4.98 & -4.88 & -5.96 & -6.22 \\
\hline Agriculture & 0.76 & -0.54 & -0.28 & -0.31 & -0.64 & -0.68 \\
\hline Mining & -3.15 & -4.93 & -5.64 & -5.47 & -7.36 & -7.69 \\
\hline Communications & -1.48 & -1.47 & -1.84 & -1.76 & -2.23 & -2.25 \\
\hline $\begin{array}{l}\text { Transportation } \\
\text { Non-manuf- }\end{array}$ & -0.33 & -1.75 & -1.41 & -1.54 & -2.13 & -2.25 \\
\hline Easy-to-measure & -1.66 & -2.56 & -2.72 & -2.68 & -3.50 & -3.64 \\
\hline Manufacturing & -0.34 & -0.56 & -0.51 & -0.51 & -0.81 & -0.87 \\
\hline Hard-to-Measure & -1.35 & -1.21 & -1.03 & -1.06 & -1.36 & -1.45 \\
\hline Construction & -0.4 & -0.91 & -0.74 & -0.77 & -0.38 & -0.08 \\
\hline Wholesale Trade & -0.66 & -0.59 & -0.62 & -0.62 & -1.59 & -2.1 \\
\hline Retail Trade & -1.41 & -1.48 & -1.48 & -1.47 & -1.83 & -1.93 \\
\hline Finance & -1.72 & -1.44 & -0.99 & -1.05 & -1.32 & -1.44 \\
\hline Services & -1.57 & -1.17 & -1.09 & -1.1 & -1.28 & -1.24 \\
\hline
\end{tabular}

Increase in the annual growth rate of TFP (column 1) and Z (columns 2 to 6) between the periods 1960-70 and 1970-97 for the different sectors in the private non-residential sector. The growth rate of disembodied productivity is computed as the residual in labor productivity after taking into account the contribution of Jelly capital (equation (11)). To identify embodied productivity, I use the following parameterizations on the discount rate: the rate of return on BAA bonds (column 2), the expected stock returns (column 3), the average between the returns to the BAA corporate bonds and the expected stock returns weighted by the sector specific debt-asset ratio (column 4), a hurdle rate that is 36 percent higher than the rate used in column 4 (columns 5), and a hurdle rate that is 41 percent higher than the rate used in column 4 (column 6). In columns 5 and 6, I introduce adjustment costs as in Bessen [2002] with a coefficient $\gamma$ of 0.2 in column 5 and 0.3 in column 6 . 
Table 5: Disembodied productivity growth with complementarity and mismeasurement.

Panel A.

\begin{tabular}{c|cccc}
\hline Bias & 0 & 0.5 & 1 & 1.5 \\
\hline Elasticity & & & & \\
1 & 2.86 & 2.36 & 1.86 & 1.36 \\
0.95 & 3.12 & 2.58 & 2.06 & 1.53 \\
0.9 & 3.45 & 2.85 & 2.27 & 1.7 \\
0.85 & 3.89 & 3.2 & 2.54 & 1.9 \\
0.8 & 4.54 & 3.69 & 2.89 & 2.15 \\
0.75 & 5.63 & 4.43 & 3.4 & 2.5 \\
0.7 & 8.44 & 5.87 & 4.24 & 3 \\
\hline
\end{tabular}

Panel B.

\begin{tabular}{c|rrr}
\hline Bias & \multicolumn{1}{c}{0.5} & \multicolumn{1}{c}{1} & 1.5 \\
\hline Elasticity & & & \\
1 & 0.5 & 0.5 & 0.5 \\
0.95 & 0.54 & 0.52 & 0.53 \\
0.9 & 0.6 & 0.58 & 0.57 \\
0.85 & 0.69 & 0.66 & 0.64 \\
0.8 & 0.85 & 0.8 & 0.74 \\
0.75 & 1.2 & 1.03 & 0.9 \\
0.7 & 2.57 & 1.63 & 1.24 \\
\hline
\end{tabular}

Panel A: Average growth rate of disembodied productivity in the private non-residential sector for several values of the elasticity of substitution between $\mathrm{J}$ and $\mathrm{L}$, and several artificial biases in the annual growth rate of the output deflator - keeping constant the level of nominal output. Panel B: decline in the average growth rate of disembodied productivity due to the "artificial" upward bias in the output deflator. In both panels, the identification of embodied productivity is conducted by calibrating the interest rates to the average between the returns to the BAA corporate bonds and the expected stock returns weighted by the debt-asset ratio. 
Table 6: Disembodied productivity growth across sectors with complementarities.

\begin{tabular}{l|ccc}
\hline Elasticity of substitution & 1 & 0.95 & 0.9 \\
\hline Private Non-Residential & 2.86 & 2.58 & 2.85 \\
Easy-to-Measure & $\mathbf{2 . 9 0}$ & $\mathbf{2 . 4 2}$ & $\mathbf{2 . 4 5}$ \\
Utilities & 1.60 & 0.73 & 0.41 \\
Agriculture & 3.54 & 2.85 & 2.54 \\
Mining & 1.01 & 0.20 & -0.11 \\
Communications & 2.26 & 1.39 & 0.95 \\
Transportation & 2.52 & 1.88 & 1.65 \\
Non-manuf- & & & \\
Easy-to-measure & $\mathbf{2 . 2 1}$ & $\mathbf{1 . 4 3}$ & $\mathbf{1 . 0 9}$ \\
Manufacturing & 3.34 & 3.05 & 3.30 \\
Hard-to-Measure & $\mathbf{2 . 6 0}$ & $\mathbf{3 . 2 8}$ & $\mathbf{3 . 5 1}$ \\
Construction & 2.87 & 3.89 & 7.33 \\
Wholesale Trade & 4.14 & 4.55 & 6.16 \\
Retail Trade & 1.85 & 1.58 & 1.86 \\
Finance & 3.31 & 5.20 &. \\
Services & 1.33 & 1.25 & 1.89 \\
\hline
\end{tabular}

Percentage annual growth rate of disembodied productivity for the period 1960-97 for the different sectors. In order to identify embodied productivity, I impose a CES production function with several elasticities of substitution between J and $\mathrm{L}$, no adjustment costs, and a discount rate equal to the average between the returns to the BAA corporate bonds and the expected stock returns weighted by the sector specific debt-asset ratio. 